\title{
17. Elusive appeal or aspirational ideal? The rhetoric and reality of the 'collaborative turn' in public policy
}

\section{Janine O’Flynn}

Collaboration is like cottage cheese. It occasionally smells bad and separates easily. ${ }^{1}$

Apparently, there has been a 'collaborative turn' in public-policy circles. We have been informed that governments around the world must develop capabilities to be in a state of 'perpetual collaboration' if they are to competently face the looming challenges of the twenty-first century (Cortada et al. 2008), and that 'the future belongs to those who collaborate' (Economist Intelligence Unit 2007:4). The collaborative 'buzz' surrounding government (Wanna 2007) was even to be heard at the Australian Government's 2020 Summit in April 2008, at which the notion of collaborative governance was elevated as a 'top idea' that could propel the nation through the next decade or so (Commonwealth of Australia 2008). Prime Minister Kevin Rudd also hinted at the importance of collaboration when he addressed the Future Summit in May 2008, where he noted that there was a profound transformation afoot. ${ }^{2}$ Clearly, collaboration is on the agenda.

What, however, is collaboration? Are we really witnessing a fundamental transformation in the way government addresses the challenges of the twenty-first century, or has collaboration become the latest fad to penetrate the Public Service? The purpose of this chapter is to reflect on the contributions to this monograph and consider such questions. My argument here is not to suggest that collaboration in government is a myth, or that collaboration is not happening on the ground. Rather, my intention is to engage in a more realistic and useful discussion of the various ways in which we might work together.

\section{The obsession with collaboration}

The attention collaboration is receiving could lead us to think that it represents a fundamental shift in how government and public-sector organisations operate and that the collaboration era has, or will soon, arrive: that a collaborative turn has occurred. A range of drivers has been identified to explain the popularity of collaboration (see Wanna, this volume), however, government interest has been summarised into three key propositions, each offering pay-offs in efficiency or effectiveness (Entwistle and Martin 2005): ${ }^{3}$

- collaboration can encourage trust and thus reduce conflict 
- collaboration can 'unlock' the distinctive competencies of other sectors

- collaboration can deliver a transformational approach to service improvement.

Some have argued that there is a need for public-sector organisations to develop the capabilities to engage in perpetual collaboration (Cortada et al. 2008), while others have pointed to the rhetoric of collaborative governance accompanied by constant complaining about the difficulty of collaborating in practice (Huxham et al. 2000). Whether you believe collaborative governance represents the next wave of thinking or is a painful requirement for operating in the modern public service, there is no doubt that it has reached fever pitch. All this heralding of a new era, however, glosses over what many already suspect: collaboration is nothing new in the public sector even if some are positioning it at the centre of a post-new public management paradigm (for example, Denhardt and Denhardt 2000; Osborne 2006).

These ideas have been rolled in to the notion of 'collaborative public management', for example, which has been defined as 'the process of facilitating and operating in multiorganizational arrangements in order to remedy problems that cannot be solved - or solved easily - by [a] single organization' (McGuire 2006:3). Such an approach pushes collaboration front and centre and the focus on some of the seemingly intractable social problems challenging government has fuelled an interest in collaboration (see, for example, Australian Public Service Commission 2007). Interestingly, Bryson et al. (2006) have argued that the obsession with collaboration has provoked two distinct responses: 1) collaboration has become the holy grail, the 'one best way' of doing everything regardless of whether there is any evidence that it will add value; or 2) collaboration occurs where all else fails - that is, organisations fail into collaboration as a last resort when other approaches don't work. Neither, of course, provides as especially convincing basis for investing in collaborative endeavours.

With the current flurry around collaboration in public policy, we need to take time to look at what others have been doing in areas in which collaboration has been central to research and practice for decades. Reviewing a range of approaches shows that collaboration has been seen as a response to resource interdependencies, a means of pooling existing resources or of leveraging new ones, a strategy to reduce risk or enter new markets, an attempt to reduce transaction costs, a reaction to complexity or turbulent environments or a search for (re)integration in a fragmented domain (see, for example, Bryson et al. 2006; Lawrence et al. 1999; Lowndes and Skelcher 1998). There are well-established literatures on joint ventures, strategic alliances, hybrids and the like, which offer great potential, especially where we are concerned with issues such as inter-organisational trust and the costs of working together (for example, White 
2005, who examines 'cooperation costs'). It would serve us well to revisit these rather than be blinded by the positive rhetoric of collaboration.

Indeed, McGuire (2006) points out that even within public policy, collaboration is nothing new. For example, in the mid-1970s, Schermerhorn (1975:846), writing in The Academy of Management Journal, noted that interagency cooperation was seen as the panacea to the 'coordination gap' that had emerged from duplication, overlap and fragmentation in social services in an increasingly 'turbulent environment'. Sound familiar? A similar rationale was noted in Bryson et al. (2006): collaboration was seen as the way to address complex problems in a complex world. The authors mindfully stated, however, that collaboration was no panacea. A similar point is made by Lundin (2007), who shows that inter-organisational cooperation is reasonable and beneficial in situations in which there is significant task complexity; enacting cooperative or collaborative approaches for simple-task situations is neither useful nor quantitatively beneficial. Rather, it is common to incur high costs. As Huxham has noted elsewhere: 'Collaboration is not a panacea for tackling all organizational activities. Most of what organizations strive to achieve is, and should be, done alone' (Huxham 1996:3). As the buzz around collaboration intensifies, however, it seems that such views are being sidelined.

Reviewing research on collaboration, it is clear that public-policy scholars and practitioners, for the most part, don't spend much time outside their disciplinary silos. In an ideal world, our current interest in collaboration should lead us to explore these perspectives; there has been so much written on collaboration that it seems nonsensical to start from scratch in public policy. Unfortunately, it is generally accepted that there is little cross-pollination, integration or, dare I say it, collaboration between these fields (for example, Hardy et al. 2003; Huxham and Vangen 1998, cited in Williams 2002). As the editors of a recent special issue of Public Administration Review noted, the idea of collaborative public management is studied largely without the benefit of examining the literature in related fields (Bingham and O'Leary 2006). In the concluding contribution to that collection, the authors suggested that 'we tend to play cooperatively each with our own set of blocks...we do not generally pool our blocks to build a common structure collaboratively' (Bingham and O'Leary 2006:161). We spend limited time looking to our colleagues in other disciplines and non-public sector worlds to help us on our way in understanding the promise and challenge of collaboration. To date, such 'collaborative' learning has been fairly limited, but great potential exists for interdisciplinary lessons.

\section{What's in a word?}

If every galah in every pet shop was once squawking the mantra of micro-economic reform, today officials in every agency are singing the tune of collaborative harmonies. (Wanna 2007:30) 
Collaboration has become so central to our conversations about public policy that few see the need to either define it or unpack what it means: collaboration has truly become part of the Zeitgeist. While many formal definitions exist, the term is used loosely by public-policy scholars and practitioners. In the Australian Public Service Commission (2007) report Tackling Wicked Problems, a collaborative approach is argued to be central to addressing these complex, inter-agency, inter-jurisdictional puzzles, yet collaboration itself is never defined. The Management Advisory Committee (2004:10) report Connecting Government similarly makes the case for the Australian Public Service (APS) to 'strive to create a "culture of collaboration"', to orient towards collaborative approaches and for secretaries to model collaborative behaviour, but it doesn't provide much in the way of telling us what collaboration really is. This relative fuzziness warrants, I believe, a discussion of the distinctive characteristics of collaboration.

As a starting point, we must accept that there is a range of means of working together, many of which are not collaborative. Further, we must also accept there is a current trend to call all forms of working together 'collaboration'. There are, however, important distinctions to make - the most important being that working together does not equal collaboration. ${ }^{4}$ This is an important point to emphasise, not just to enable some sort of academic language game, but because collaboration has become $d u$ jour. A more measured analysis, drawing on the extensive existing literature, might point us to make some very different judgments about whether what we are witnessing is cooperation, coordination or, in some cases, coercion. From here, then, we can be more realistic about why organisations work together, when this might be appropriate and how they might go about really doing it. At the most basic level, understanding what we mean by collaboration is important to ensure we are talking the same language.

Collaboration has been defined as 'a process in which organizations exchange information, alter activities, share resources, and enhance each other's capacity for mutual benefit and a common purpose by sharing risks, responsibilities, and rewards' (Himmelman 2002:3). For others, it is an 'interorganizational relationship that relies on neither market nor hierarchical mechanism[s] of control but is instead negotiated in an ongoing communicative process' (Lawrence et al. 1999:481). In the public-policy world, where terms such as collaborative governance are used, the collaborative part of the term becomes fairly loose: for example, Donohue (2004:2) describes collaborative governance as an 'amalgam of public, private and civil society organizations engaged in some joint effort'. What tends to get lost is the distinctiveness of collaboration. Collaboration is not just a model of service delivery, it is something more complex, which involves sharing across a range of dimensions (for example, goal setting, risk, reward, resource, culture) a more strategic nature and autonomy (Head 2004, 2006; Axelrod 1984, 1997; Economist Intelligence Unit 2008; Shergold, this volume). 
Understanding its distinctive features helps us to better see what collaboration is and what it is not.

Various typologies are available to assist in distinguishing collaboration and I will mention just a few - the common feature being that collaboration sits at the extreme end of different models of working together. Mattessich and Monsey (1992:39), for example, make clear distinctions between cooperation, coordination and collaboration. Cooperation is described as an informal relationship without a common mission in which information is shared on an as-needed basis, authority remains with each organisation, there is little (or no) risk and resources and rewards are kept separate. Coordination is seen as more formal and there are compatible missions that require some common planning and more formal communication channels. While each organisation retains authority, risk enters the equation. Collaboration is a more 'durable and pervasive relationship' (Mattessich and Monsey 1992:39), which involves creating new structures within which to embed authority, developing a common mission, engaging in comprehensive and shared planning, and in which formal communication across multiple levels occurs. Collaboration includes pooling and jointly acquiring resources, sharing rewards, but also increased risk. Clear distinctions are made here, which for our purposes help to delineate collaboration and differentiate it from other engagement strategies such as cooperation and coordination.

Similar distinctions were made by Himmelman (2002:1-5), who made the case that collaboration was just one of four common strategies for working together, ${ }^{5}$ each representing a unique inter-organisational linkage, requiring different commitments of trust, time and turf. Each is more or less appropriate in different circumstances. In brief, the strategies are:

- Networking is an informal relationship in which information is exchanged for mutual benefit. This choice often reflects limited time, low levels of trust and a reluctance to share or concede turf. Himmelman uses the example of an early childhood centre and a public health department exchanging information about their approaches to supporting early childhood development. In this volume, Sylvan (Chapter 14) provides a good example with the Australasian Consumer Fraud Taskforce, which, at least in its initial stages, was an informal information-sharing forum.

- Coordination ${ }^{6}$ involves a more formal linkage in which information is exchanged and activities are altered in pursuit of mutual benefit and achievement of common purpose. Compared with networking, it involves more time and higher trust, but little or no access to one another's turf. Himmelman suggests that when the two parties mentioned above then decide to alter their service schedules to provide combined support in a more user-friendly way, this constitutes coordination. A good example mentioned 
in this volume and one mentioned by several authors is the Australian Government's Job Network.

- Cooperation involves an exchange of information, altering activities and resource sharing for mutual benefit in pursuit of a common purpose. Organisational commitments are higher, formal agreements can be used and this linkage requires higher levels of time and trust vis-à-vis networking and coordination. Each party will provide access to its turf. If the two parties Himmelman discusses now agree to share outreach services to increase the overall effectiveness of their support for early childhood development, this represents cooperation. This volume provides several examples, including the family violence strategy discussed by Treadwell (Chapter 12) and the Homeless Connect project described by Allison (Chapter 13).

- Collaboration is distinctive as it involves a willingness of the parties to enhance one another's capacity-helping the other to 'be the best they can be' (Himmelman 2002:3) - for mutual benefit and common purpose. In collaboration, the parties share risks, responsibilities and rewards, they invest substantial time, have high levels of trust and share common turf. Where Himmelman's two organisations now agree to provide skill-development training for the staff of the other organisation to enhance capacity and enable improved support for early childhood development, this reflects collaboration. In this volume, it was difficult to identify a case of collaboration on these terms; however, it could be argued that Carmody's (Chapter 7) discussion of crisis management comes closest.

In their work on collaboration in inter-organisational domains, Hardy and Phillips (1998) identify different engagement strategies, two of which I will note here. First, they discuss collaboration as a mutual engagement strategy in which parties participate voluntarily and, second, they contrast this with a compliance strategy in which a dominant party (for example, government) can use its power to regulate a weaker party (for example, a community group), who, essentially, has little or no choice about engaging. In other work, Hardy et al. (2003) stress the point that while collaboration can exist in many different organisational forms (for example, joint ventures, alliances, consortia, networks), it must be distinguished from cooperation, which can be purchased (for example, from a supplier) or demanded via some form of legitimate authority (for example, by a government organisation).

Power is, of course, a critical issue, and one that is remarkably absent from much of the public-policy writing to date. As Hardy and Phillips (1998) define it, genuine collaboration relies on voluntary and mutual engagement; others discuss how true collaboration involves autonomy, trust, mutual goal setting, and so on. In contrast, there are other forms of engagement that can be more, or less, voluntary and equal. The current trend, however, towards labelling all forms 
of interaction collaboration paints a more upbeat picture, in which collaboration is virtuous and equal. The more critical work on collaboration rejects much of this, suggesting, for example, that issues of power asymmetry, exploitation and repression (Hardy and Phillips 1998) need to be factored into our analyses of how 'real' collaboration is. Sylvan (Chapter 14) raises the issue of power and points to the challenges of power sharing, including operating in domains in which powerful stakeholders hold vested interests. Henry (Chapter 11) comes at the issue from a different perspective. She acknowledges the fact that community organisations are often seen as unequal partners in their dealings with government organisations, and to some extent this is true, because regardless of whether they hold strategic assets that the government requires, they are still heavily reliant on funding to continue, and government still remains in the position to, essentially, change its mind.

In the preceding discussion, I sought to clarify the distinctiveness of collaboration from other forms of engaging or working together. This is not a purely academic exercise, but rather a means of better analysing the contributions to this monograph. In the next section, I reflect on the general trend towards collaborative government and the more specific contributions made here to highlight this point.

\section{Reflections on 'collaboration' in practice: what can we learn?}

In reviewing the narratives captured in this monograph, it is not at all clear that 'collaboration' is evident. Rather, we have a collection of inter-organisational relationships of which few, if any, we would genuinely describe as collaboration. More likely is the case that these examples combine aspects of networking, coordination and cooperation (with some coercion or compliance in the mix). This could reflect the fact that 'surface dynamics are not necessarily an accurate description of what is going on beneath' (Hardy and Phillips 1998:217); in other words, while everyone is talking collaboration is anyone really collaborating?

Reflecting on these contributions suggests two critical things. First, government working with, or through, other parties is an increasingly popular mode of policymaking and implementation; and second, few of these relationships could rightly be described as collaborative. Just as Jupp (Chapter 16) suggested 'partnership' was the dominant rhetoric of the Blair Government in the United Kingdom, so we see that collaboration has the potential to explode in a similar way in Australia. Jupp acknowledges that there is a spectrum of engagements between government and third-sector organisations, however, even here they are all labelled as collaboration. There is, of course, nothing to suggest that government-NGO relations cannot be collaborative, but whether the use of commercial-style contracts for the delivery of public services is inherently collaborative is open to debate. In many cases, it could be more accurate to 
suggest that government is simply purchasing cooperation from a provider organisation (see Hardy et al. 2003). In the examples provided by Allison (Chapter 13), we can identify a range of engagement strategies between organisations and individuals, including public-private partnerships (PPPs), integrated services for the homeless, technology-based co-production of services and community-engagement forums. Based on the prior discussion, we can see that these represent a spectrum of connections and examples of working together, but it is hard to accept that these are all collaborative in the manner set out above. More likely, we have a mixed bag of co-production, coordination and cooperation. Perhaps Treadwell's (Chapter 12) example of addressing family violence comes close to collaboration, but, using Himmelman's (2002) typology, it is more likely cooperation.

If we use Hardy and Phillip's (1998) descriptors, we can see a strong case from Smith (Chapter 9) that there has been a radical departure in Indigenous affairs from collaboration towards compliance: a dominant party regulates a weaker one. Of course, interpretations depend on where you stand. Similarly, Shergold's (Chapter 2) discussion of Shared Responsibility Agreements (SRAs) is another area in which there are competing views of the extent of collaboration: are they really collaborative arrangements between government and Indigenous communities, or are they simply new compliance instruments? Shergold himself notes that while they require a commitment to consultation and negotiation, they would be much more effective if they were more genuinely collaborative. This, of course, would require ingredients such as mutual trust, shared resources, mutually agreed goals, voluntary participation and the sharing of risk and reward, for example. The practicalities of such an approach appear, at this stage in history, to be remote.

Hodge and Greve's (Chapter 10) contribution challenges the rhetoric of collaboration in PPPs; indeed, it poses a range of questions about how government and the private sector work together. The authors clearly argue that PPPs have, in many cases, been two-way deals between government and business, governed by complex, often unintelligible, commercial-in-confidence contracts. At worst, they force us to ask whether they are the outcome of the political and business interests that go against the best interests of the citizenry - a unique collaboration indeed! At the very least, we must question whether there is any collaboration happening here at all. Using the notions discussed above, at best, we might see coordination or cooperation emerging from these arrangements. Similarly, questions must be raised when we consider the issues canvassed in the education domain - and, in her contribution, Hunter (Chapter 8) points to a powerful set of institutional barriers to collaboration.

From the community sector, Henry (Chapter 11) raises questions about the effects of contractualisation on relationships between government and non-profit 
organisations. Is it possible that the shift towards wrapping contracts around previously grant-based relationships or inviting non-profits to enter the 'market' for services has produced a net collaborative loss in the third sector? Competition between previously collaborative non-profits in the quest for government contracting could, in fact, reduce collaboration within the sector. Smyth picks up this issue when he argues that the Job Network has been assessed as being 'overly centralised with excessive regulation'; it also ignores 'unique local circumstances and directs activity away from collaboration... and networking' (Chapter 6). This, of course, raises a broader question of just how collaborative government contracting really is. In his contribution, Shergold mentions the potential for compliance-style relationships - which have characterised the Job Network - to be transformed into more collaborative arrangements. Collaboration, he notes, will prepare the ground for 'innovation and continuing improvement in the long term' (Chapter 2). The trick, of course, will be in trying to set and shift incentives in what has been a quasi-market, where providers have competed against one another for business and for higher performance ratings. In some ways, this might represent a return to collaboration for some of the non-profit organisations, rather than some new collaborative discovery. In his discussion on developments in Canada, Lindquist (Chapter 15) notes the promise of government-voluntary sector relations, but also points to a range of challenges.

Regardless of whether we classify these examples as 'genuine' collaborations or not, there are important lessons to be drawn from the contributions about working together constructively. One of the most interesting and most novel lessons comes from Huxham and Hibbert (Chapter 5), who ask a basic yet often overlooked question: what will success look like for the parties to collaboration? Will it be the achievement of outcomes, getting processes to work, reaching milestones, gaining external recognition or a personal pride that develops from successfully championing a project? This is an important issue, because without this discussion partners will find that their measures of success will differ; success is, in the end, different things to different people.

It is also important to be realistic about the trade-off between effort and reward. As strategies for working together become more complex - that is, they move towards the collaborative end of the scale - investments and costs intensify. Our contributors remind us that there are many costs associated with inter-organisational work or working across formal boundaries and these occur regardless of whether 'success' is achieved. At the most basic, this can involve time, travel and other communication costs and participants can suffer 'partnership fatigue' (Huxham and Vangen, Chapter 4). More significantly, there can be costs to employees, clients or communities who must deal with dysfunctional experiments. As Huxham and Vangen explain, the potentiality of collaborative advantage must be weighed against the hard grind of genuine collaboration or, in their words, collaborative inertia. 
Recognising the specific capabilities and strategic assets of different parties is important when engaging in different modes of operation. Henry (Chapter 11) reminds us that non-profit community organisations often hold the critical intelligence and access that government organisations need, and implies that they must learn to leverage this more fully in their relationships with governments. Within this context, especially where there are commercial contracts in place, such organisations need to be wary of becoming 'semi-state agencies', as Jupp warns (Chapter 16). This goes back to some of the basic ideas of collaboration; it involves autonomous agents working together to achieve mutual goals, not the takeover of supposed partners. Again, recognising the issue of power asymmetries is crucial in developing a more sophisticated understanding of the realities of working together; it is too easy to just assume such differentials away. Huxham and Vangen (Chapter 4), however, remind us that it is not just the 'purse strings' that produce power; there are multiple points where power is important when we work together. Power asymmetries do exist and provide the basis for, in some cases, 'collaborative thuggery' (Huxham and Vangen, Chapter 4).

It is important to consider conditions for effective joint work. Carmody (Chapter 7) points us to the power of a crisis to propel parties towards a more collaborative space - a point reinforced by Allison (Chapter 13), who argues that the water crisis has enabled radical changes in behaviour. Such situations permit a 'take-charge' attitude and set the scene for the key ingredients Carmody identifies: effective leadership, clear identification of responsibilities, common accountabilities, clear communication channels, rehearsed processes, a common agenda and depoliticised arenas in which there is no room for ideology. While such ingredients prepare the ground for an effective 'institutional architecture of crisis management', they are often missing in longer-term, non-crisis situations. Rather, as Carmody notes, they mirror common military practice and, in non-crisis situations, would go against many of the suggested models for genuine collaboration. Of course, the identification of a crisis can permit radical change in non-military situations - the NT intervention of 2007 providing a recent example.

Outside crisis situations, the sustainability of collaborative efforts is an important topic. How are these relationships cultivated, nurtured and sustained over time? How do we ensure continuity when there is turnover of people engaged in different types of 'working together'? Such questions point to the inevitable 'people issue'. When we get down to it, it is people who enable organisations to work together effectively, sometimes despite organisational barriers. Several contributors point to the importance of 'people' factors-for example, Fels (Preface) and Eggers (Chapter 3) identify the new skills needed by those who engage in more network-style arrangements, and other contributors stress a range of skills that needs to be enhanced-usually on the government side of 
arrangements - to enable more productive and effective engagement between parties. Sylvan (Chapter 14) cautions that we need to be aware of the people problems that can emerge when power relations change and how incentives for working together need to be carefully thought out. Clearly, collaborative capacity is a serious issue - as Fels (Preface) points out - and new thinking is required for us to enable more productive working relationships.

A final lesson is based on the cautionary messages that were included in several of the contributions to this volume. With all the hype around collaboration, it is tempting for many to see it as some panacea, as an optimal operating model in what are seen as complex and turbulent times. Prescribing collaboration as the 'one best way' to work together is, however, fraught, as Head has argued elsewhere: 'Selection of inappropriate structures and processes can be a recipe for frustration among participants, and ensures under-achievement of goals' (2004:3). Put more succinctly: '[D]on't work collaboratively unless you have to' (Huxham and Vangen 2004:200). Of course, this is more easily said than done: when and where to collaborate (and with whom) are, in practice, some of the most difficult questions of all.

Looking forward, it will be interesting to watch whether the recent change of government will provide some collaborative impetus; certainly, the noise early on revolves around how the new government will seek to 'work together' with many different groups. This is not to say that the previous government was not interested in collaboration; in fact, many of the examples provided in this monograph suggest the opposite. For some, the NT intervention showed how government agencies could come together to address social issues, and changes over time in the Job Network showed some development along the collaboration spectrum. One of the great challenges for this government will be in intergovernmental collaboration and whether it can address complex policy problems.

\section{Concluding remarks}

There appears to be little evidence from the preceding contributions that we are entering a new era. At best, we could be at the beginning of some evolutionary process that will propel us, in time, towards more genuinely collaborative approaches. This is a point made most strongly in Shergold's contribution (Chapter 2), in which he cautions us against exaggerating the speed of process or the substance of change. Strong demarcations still exist, bureaucratic barriers remain and governments retain extensive powers of control. Such factors make collaboration difficult, partially, at least, because it is always possible for government to 'trump' its supposed partners or to change its mind if it so wishes. Smith provided the perfect example of this when she told us: 'In one day, without any consultation [the Bininj leaders from the West Arnhem Shire learned that 
their] collaboration with the Australian Government had essentially been made null and void' (Chapter 9).

The complexity of collaboration is very real but a serious problem is emerging in the scholarly and practitioner worlds. The current trend towards labelling all forms of working together collaboration glosses over the messy, uneven world in which we operate and, if we fail to disentangle these complexities, we will never get a handle on what is really going on. Our opportunities to learn will be stymied and our ability to consider appropriate models for inter-organisational and cross-sectoral work will be hampered. The challenges and the promise make collaboration appealing indeed, but perhaps Head (2004) is right: we should consider collaboration an aspirational ideal.

\section{References}

Australian Public Service Commission 2007, Tackling Wicked Problems: A public policy perspective, Australian Government, Canberra.

Axelrod, R. 1984, The Evolution of Cooperation, Basic Books, United States of America.

Axelrod, R. 1997, The Complexity of Cooperation: Agent-based models of competition and collaboration, Princeton University Press, Princeton, New Jersey.

Bingham, L. B. 2006, 'The new urban governance: processes for involving citizens and stakeholders', Review of Policy Research, vol. 23, no. 4, pp. 815-26.

Bingham, L. B. and O'Leary, R. 2006, 'Parallel play, not collaboration: missing questions, missing connections', Public Administration Review, vol. 66, no. sl, pp. 161-7.

Brown, K. and Keast, R. 2003, 'Citizen-government engagement: community connection through networked arrangements', Asian Journal of Public Administration, vol. 25, no. 1, pp. 107-31.

Bryson, J. M., Crosby, B. C. and Middleton Stone, M. 2006, 'The design and implementation of cross-sector collaborations: propositions from the literature', Public Administration Review, vol. 66, no. sl, pp. 44-55.

Commonwealth of Australia 2008, Australia 2020 Summit: Initial summit report, April, Canberra, viewed 21 April 2008, <http://www.australia2020.gov.au/report/index.cfm>

Cortada, J. W., Dijkstra, S., Mooney, G. M. and Ramsey, T. 2008, Government 2020 and the Perpetual Collaboration Mandate: Six worldwide drivers demand customized strategies, IBM Institute for Business Value, IBM Global Services, New York. 
Denhardt, R. B. and Denhardt, J. V. 2000, 'The new public service: serving rather than steering', Public Administration Review, vol. 60, no. 6, pp. 549-59.

Donahue, J. 2004, On collaborative governance, Corporate Social Responsibility Initiative Working Paper No. 2, John F. Kennedy School of Government, Harvard University, Cambridge, Mass.

Economist Intelligence Unit 2007, 'Collaboration: transforming the way business works', The Economist, London, viewed 7 April 2008, $<$ http://www.eiu.com/site_info.asp?info_name=Collaboration_ Transforming_the_way_business_works\&rf $=0>$

Economist Intelligence Unit 2008, 'The role of trust in business collaboration', The Economist, London, viewed 7 April 2008, $<$ http://www.eiu.com/site_info.asp?info_name=cisco_trust\&page=noads $>$

Entwistle, T. and Martin, S. 2005, 'From competition to collaboration in public service delivery: a new agenda for research', Public Administration, vol. 83, no. 1, pp. 233-42.

Hardy, C. and Phillips, N. 1998, 'Strategies of engagement: lessons from the critical examination of collaboration and conflict in an interorganizational domain', Organization Studies, vol. 9, no. 2, pp. 217-30.

Hardy, C. Phillips, N. and Lawrence, T.B. 2003, 'Resources, knowledge and Influence: the organizational effects of interorganizational collaboration', Journal of Management Studies, vol. 40. no.2, pp. 321-347.

Head, B. 2004, Collaboration - What We Already Know, and How to Do It Better, Australian Research Alliance for Children and Youth, 20 January, viewed 7 April 2007, <http://www.aracy.org.au/>

Head, B. 2006, Effective Collaboration, Australian Research Alliance for Children and Youth, July, viewed 7 April 2007, <http://www.aracy.org.au/>

Himmelman, A. T. 2002, Collaboration for a Change: Definitions, decision-making models, roles, and collaboration process guide, Himmelman Consulting, Minneapolis.

Huxham, C. (ed.) 1996, Creating Collaborative Advantage, Sage, London.

Huxham, C. and Vangen, S. 2004, 'Doing things collaboratively: realizing the advantage or succumbing to inertia?', Organizational Dynamics, vol. 33, no. 3, pp. 190-201.

Huxham, Chris., Vangen, S., Huxham, C. and Eden, C. 2000, 'The challenge of collaborative governance', Public Management Review, vol. 2, no. 2, pp. 337-58. 
Lawrence, T. B., Phillips, N. and Hardy, C. 1999, 'Watching whale watching: exploring the discursive foundations of collaborative relationships', Journal of Applied Behavioral Science, vol. 35, no. 4, pp. 479-502.

Lowndes, V. and Skelcher, C. 1998, 'The dynamics of multi-organizational partnerships: an analysis of changing modes of governance', Public Administration, vol. 76, no. 2, pp. 313-33.

Lundin, M. 2007, 'When does cooperation improve public policy implementation?', The Policy Studies Journal, vol. 35, no. 4, pp. 629-52.

Management Advisory Committee 2004, Connecting Government: Whole of government responses to Australia's priority challenges, Australian Government, Canberra.

Mattessich, P. W. and Monsey, B. R. 1992, Collaboration: What makes it work, Amherst H. Wilder Foundation, St Paul, Minnesota.

McGuire, M. 2006, 'Collaborative public management: assessing what we know and how we know it', Public Administration Review, vol. 66, no. s1, pp. 33-43.

O'Leary, R. and Bingham, L. B. 2007, A Manager's Guide to Resolving Conflicts in Collaborative Networks, IBM Center for the Business of Government, Washington, DC.

Osborne, S. 2006, 'The new public governance?', Public Management Review, vol. 8, no. 3, pp. 377-87.

Powell, W. W., Koput, K. W. and Smith-Doerr, L. 1996, 'Interorganizational collaboration and the locus of innovation: networks of learning in biotechnology', Administrative Science Quarterly, vol. 41, no. 1, pp. $116-45$.

Rittel, H. W. J. and Webber, M. M. 1971, 'Dilemmas in a general theory of planning', Policy Sciences, vol. 4, pp. 155-69.

Schermerhorn, J. R. 1975, 'Determinants of interorganizational cooperation', Academy of Management Journal, vol. 18, no. 4, pp. 846-56.

Thomson, A. M. and Perry, J. L. 1998, 'Can AmeriCorps build communities?', Nonprofit and Voluntary Sector Quarterly, vol. 27, no. 4, pp. 399-420.

Wanna, J. 2007, 'Governments abuzz with collaborative harmonies', Public Sector Informant/The Canberra Times, 3 July, pp. 30-1.

White, S. 2005, 'Cooperation costs, governance choice and alliance evolution', Journal of Management Studies, vol. 42, no. 7, pp. 1383-412.

Williams, P. 2002, 'The competent boundary spanner', Public Administration, vol. 80, no. 1, pp. 103-24. 


\section{ENDNOTES}

1 Program director quoted in Thomson and Perry (1998:409).

2 Keynote address by Prime Minister Kevin Rudd at the Australian Davos Connection Future Summit 2008, 11 May 2008, Hilton Hotel, Sydney.

${ }^{3}$ While the authors use the term 'partnership', their propositions are all linked explicitly to collaboration; collaboration is the centrepiece of partnership in the UK context.

4 This is generally held to be the case despite a recent publication from The Economist stating that 'collaboration is to work together - to co-labour' (Economist Intelligence Unit 2007:7). Interestingly, in a 2008 publication from the Economist Intelligence Unit, The Role of Trust in Business Collaboration, the authors note that the term 'collaboration' is a misnomer and there are differences between coordination, cooperation and collaboration (see p. 2).

5 The different strategies can also be considered as developmental stages - for example, a relationship can begin as coordination, but develop with time into cooperation.

6 Readers will have noted that the placement of cooperation and coordination differs in the typologies offered by Himmelman and Mattessich and Monsey, with Mattessich and Monsey placing coordination before cooperation. 